\title{
The Expansion of Pediatric Care Through Digital Technology
}

\author{
Yolanda N. Evans ${ }^{1}\left[\right.$ [ Evelyn Eisenstein ${ }^{2}$
}

Accepted: 14 September 2021 / Published online: 2 October 2021

(c) The Author(s), under exclusive licence to Springer Science+Business Media, LLC, part of Springer Nature 2021

\begin{abstract}
In this commentary, we hope to offer examples of how technology is building connections and agencies are working creatively to reduce disparities in digital technology access to improve the lives of children and adolescents across the globe.
\end{abstract}

Keywords Digital technology $\cdot$ Telemedicine $\cdot$ Telehealth $\cdot$ eHealth $\cdot$ Telepediatrics $\cdot$ Pediatric health care

\section{Introduction}

Over the past year, the field of pediatric health has been pushed to embrace the use of digital technology to continue providing safe, effective care through a global pandemic. The use of telemedicine expanded to utilize secure video connection software and videoconference platforms that have allowed providers to connect with patients directly in their home. Mobile health applications and eHealth formats rapidly increased to meet the demands of patients and providers to track laboratory values and metrics. With these expansions in the reliance on digital health, many benefits and improvements in scientific knowledge sharing have been attained, yet many socio-economic disparities have been amplified around the world, including the digital divide. This divide includes access to high-speed broadband internet and the equipment needed to use and access services.

The manuscripts in this issue of Current Pediatrics Reports will offer novel research and expert commentary on the use of digital technology in pediatric primary and subspecialty care (Fig. 1). The submissions showcase realized potential and future innovation that will further the field of pediatric medicine and pediatric health care worldwide.

Yolanda N. Evans

Yolanda.Evans@seattlechildrens.org

Evelyn Eisenstein

evelynbrasil@hotmail.com

1 Seattle Children's Research Institute, 4540 Sand Point Way NE Suite 200, Seattle, WA 98105, USA

2 University of the State of Rio de Janeiro, Rua Bambina 124 sala 203, Rio de Janeiro, RJ 22251-050, Brazil
In this commentary, we hope to offer examples of how technology is building connections and agencies are working creatively to reduce disparities in digital technology access to improve the lives of children and adolescents across the globe.

\section{Digital Health Technology}

Digital health technology is a very broad range of categories that includes mobile health, health information technologies, wearable devices, telemedicine, and telehealth [1]. The World Health Organization has recognized the use of information and communication technologies or eHealth as one of the more rapidly growing areas in health care at present [2]. In March of 2021, the United Nations Convention on the Rights of the Child acknowledged the evolving use of the digital environment in the lives of children and the emerging and expanding importance access to digital technology has on societal function, health, and education [3]. The Committee offered four general principles in order to implement the rights of children in relation to the digital environment including (a) non-discrimination, (b) best interests of the child, (c) right to life, survival, and development, and (d) respect for the views of the child. This statement highlights the importance of digital technology in childrens' lives. The ongoing coronavirus pandemic has increased the presence of digital technology in the lives of children more than ever as many regions have relied on virtual platforms for educational instruction, provision of health-related services, and for remaining connected to friends and family in a physically distanced way. 


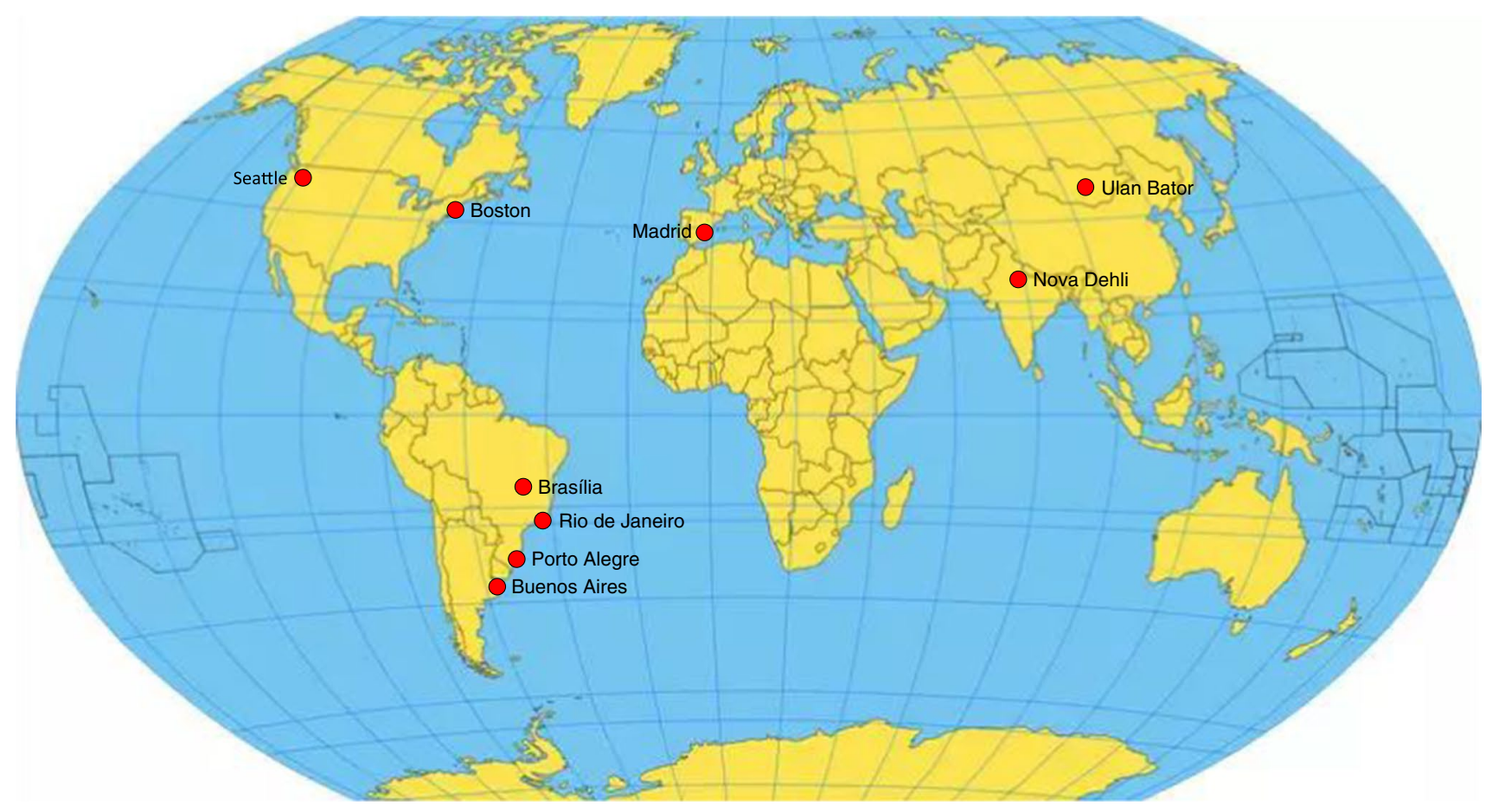

Fig. 1 Locations of contributing authors in the special edition of Current Pediatrics Reports

\section{Opportunities for Technology to Increase Access to Care}

Around the globe, there have been calls to action for improvements in the well-being of communities including communities with children and adolescents. The United Nations Development Programme (UNDP) is an example of focused improvements especially in poorer countries and remote regions and communities [4]. The UNDP works in nearly 170 countries and territories to achieve sustainable development goals (SDGs) which will allow those communities to respond to the rapidly changing environment and, hopefully, eradicate poverty. The following goals: (1) No Poverty, (2) Zero Hunger, (3) Good Health and Well-Being, (4) Quality of Education, (5) Gender Equality and Zero Discrimination against women and girls, (9) Innovation and Infra-Structure, (10) Reduced Inequalities, (11) Sustainable Cities and Communities, and (17) Partnerships and Implementation of media and technology to achieve the goals are all interlinked and intertwisted with the increase access to pediatric health care through the telehealth and telemedicine developments.

The PanAmerican Health Organization (PAHO) offers another global example of the use of digital technology for improvement in health through its Department of Evidence and Intelligence for Action in Health (EIH). There are diverse projects and publications, in English, Spanish, and Portuguese with the collaborating centers around 800 institutions, universities, and hospitals, including pediatric health care centers, "leaving no one behind" in digital transformation and public health [5].

Action in clinical care moves forward based on evidence gathered through research and education. There are agencies that have excelled recently in connecting researchers and educators while also disseminating new findings, agencies such as GEANT, which has developed national research and education networks (NREN) with partners of 39 countries and 50 million users at 10,000 institutions around Europe sharing brainpower and research skills that are urgently needed to tackle major issues, including issues in children's health [6]. In addition, consortiums such as the eHealth Task Force Building Europe Link to Latin America and Caribe (BELLA) are working to increase the interconnectivity needs of European and Latin American countries. In South America, Brazil Rede Universitaria de Telemedicina (RUTE) and RedCLARA, a consortium of research and education communities in Ecuador, Colombia, Chile, Argentina, are expanding research, education, and specialty consultation services $[7,8]$.

As the world is hyperconnected via technology, it is important to continue to emphasize the health of children. National organizations, including the American Telemedicine Association (ATA) and the International Society for Telemedicine and eHealth, are continuing to facilitate the 
international dissemination of newly achieved knowledge $[9,10]$.

\section{Enhancing Communication Between Pediatric Health care Providers and Families}

Telemedicine and Telehealth are part of this present technology leveraging a new future to decrease the health gaps between rich and poorer countries and regions. Pediatric health care has been able to utilize the commercial technology, such as wi-fi, smartphones, computers, laptops, tablets, and applications, families may have used to communicate amongst themselves prior to the pandemic. Direct to home telehealth was halted in the past by legal and regulatory principles put in place to protect patients and ensure health care providers had appropriate skill sets in an era before technology was nearly ubiquitously available. Some of these regulations have been temporarily suspended to ensure access to care during the pandemic [11]. Ethical and legal considerations combined with changes to national regulatory criteria and laws have allowed many of the previous obstacles to be surpassed so that technology has been leveraged to reach patients and families where they reside.

This Special Issue offers both novel and practical experiences in various pediatric health care settings. The future is bright for the use of technology in improving the health of pediatric patients around the world.

\section{References}

1. Food and Drug Administration. Digital health. [Online] 2020. [Cited: Sept 2, 2021.] https://www.fda.gov/medical-devices/digit al-health.

2. World Health Organization. Global observatory for eHealth. [Online] 2020. [Cited: Sept 2, 2021.] https://www.who.int/goe/ en/.

3. United Nations Convention on the Rights of the Child. [Online] [Cited: Sept 2, 2021.] https://www.ohchr.org/EN/HRBodies/CRC/ Pages/GCChildrensRightsRelationDigitalEnvironment.aspx.

4. United Nations Development Programme. [Online] [Cited: Sept 2, 2021.] https://www.undp.org/sustainable-development-goals.

5. PanAmerican Health Organization. Department of Evidence and Intelligence for action in health. [Online] [Cited: Sept 2, 2021.] https://www.paho.org/en/evidence-and-intelligen ce-action-health/.

6. GEANT. [Online] [Cited: Sept 2, 2021.] https://www.geant.org.

7. Brazil Rede Universitaria de Telemedicina. [Online] [Cited: Sept 3, 2021.] http://www.rute.rnp.br.

8. RedCLARA. [Online] [Cited: Sept 2, 2021.] http://www.redclara. net/index.php/en.

9. American Telemedicine Association. [Online] http://www.ameri cantelemed.org.

10. International Society for Telemedicine and eHealth. [Online] [Cited: Sept 3, 2021.] https://www.isfteh.org/.

11. U.S. Department of Health and Human Services. [Online] [Cited: Sept 3, 2021.] https://www.hhs.gov/coronavirus/telehealth/index. html.

Publisher's Note Springer Nature remains neutral with regard to jurisdictional claims in published maps and institutional affiliations. 